\title{
Intramuscular cavernous hemangiomas arising from masseter muscles
}

\author{
Masseter adalesinden köken alan intramuskuler kavernöz hemanjiyom
}

\author{
Hanifi Bayaroğulları ${ }^{1}$, Yaşar Çokkeser ${ }^{2}$, Ercan Akbay ${ }^{2}$, Ece Karaoğlu ${ }^{1}$, Emre Karaoğlu ${ }^{2}$, Cengiz Çevik ${ }^{2}$
}

\begin{abstract}
Intramuscular hemangiomas are rarely seen benign tumors, constituting \%1 of all hemangiomas. They mostly occur in the trunk and extremities. They are uncommon in the head and neck region and arising most frequently from masseter and trapezius muscle. The patients usually complain about progressive and painless swelling in facial-parotid region. Due to its location, $90 \%$ of all intramuscular hemangiomas are misdiagnosed and often clinically mistaken as a parotid swelling. Radiologic images play important role for diagnosis of these hemangiomas. J Clin Exp Invest 2012; 3 (3): 404-408
\end{abstract}

Key words: Intramuscular hemangioma, head and neck muscles, imaging modality.

\section{INTRODUCTION}

Intramuscular hemangioma (IMH) is believed to be hemartomatous, congenital neoplasm, and proliferation of benign vascular channels within the skeletal muscle. Intramuscular hemangiomas are very rare and constitute approximately $1 \%$ of all hemangiomas. ${ }^{1} 0.8 \%$ of all hemangioma and $10-20 \%$ of all intramuscular hemangioma are located in the head and neck muscles. ${ }^{2-4}$ They are uncommon in the head and neck region and arising most frequently from masseter and trapezius muscles. Due to the fact that IMH has nonspecific clinical findings; preoperative diagnosis is difficult. It tends to be relatively well circumscribed, and insidiously infiltrates the muscle resulting in a mass with deceptive gross margins. Inaccurate preoperative diagnosis and treatment planning may lead to an incomplete excision and unnecessary risk to facial nerve injury or bleeding.

The swelling normally diffuses in nature, is compressible and characteristically deep within the muscle. However, softness and compressibility may be absent due to local fibrosis and overlying muscu-

\section{ÖZET}

Tüm hemanjiyomların \%1'ini oluşturan intramuskuler hemanjiyomalar nadir görülen benign tümörlerdir. Sıklıkla gövde ve ekstremitelerde görülebilmektedir. Masseter ve trapezius kaslarından köken alabilen bu oluşumlar baş ve boyun bölgesinde nadir izlenmektedir. Hastalar genellikle parotis ve yüz bölgesinde zamanla büyüyen ağrısız kitleden şikayet eder. Lokalizasyonundan dolayı intramuskuler hemanjiyomaların \%90'ında klinik olarak yanlışlıkla parotis kitlesi tanısı konulabilir. Bu kitlelerin tanısında görüntüleme yöntemleri önemli yer tutar.

Anahtar kelimeler: İntramuskuler hemanjiyom, baş ve boyun kasları, görüntüleme yöntemleri.

lature. Pulsations, bruits or thrills are uncommon but when present, arteriography is indicated to identify large vessel communications.

\section{CASE REPORTS}

\section{Case 1}

A 50 years-old female patient admitted to our hospital with complaints of occasional painful swelling of the right parotid and retroauricular regions for 4 years. The swelling was revealed over the right parotid region with physical examination. It was a mobile and multilobulated surface. Her facial movements, intraoral examinations, and overlying skin were normal.

Via ultrasound examinations it was seen that there was heterogeneous echogenicity cystic mass with multiple posterior acoustic shadowing from the calcified nodular areas in the right masseter muscle. It was also seen that there was multiple lympadenopathy (LAP) in the bilateral parafarengeal and retroauricular regions. Later Computed Tomography $(\mathrm{CT})$ was planned for diagnosis. It was found

${ }^{1}$ Mustafa Kemal University Medical Faculty Department of Radiology, Hatay, Turkey

${ }^{2}$ Mustafa Kemal University Medical Faculty Department of Otolaryngology, Hatay, Turkey

Correspondence: Ercan Akbay,

Mustafa Kemal University Medical Faculty Department of Otolaryngology Hatay, Turkey Email: ercanakbay@yahoo.com Received: 26.05.2012, Accepted: 08.08.2012

Copyright (C) JCEI / Journal of Clinical and Experimental Investigations 2012, All rights reserved 
that there was a mass lesion at the location of the right masseter muscle; there was multiple round calsified area within the mass lesion (Fig. 1a-d). Multiple LAPs were seen in the bilateral parafarengeal and retroauricular regions.

For more detailed evaluation of the lesions, magnetic resonance imaging (MRI) examination was performed. The mass appeared as high signal intensity lobules that resemble a brunch of grapes on T2 weighted images. There were punctate or re- ticular low signal intensity areas that represent fibrous tissue. Fast flow within the vessel or foci of calcifications due to phlebolithes was also identified. Our case has characteristic and pathognomonic signs of hemangioma like a brunch of grapes and phlebolith(Fig. 2a-d). The mass enhanced after intravenous contrast material. Multiple LAPs were seen in the bilateral parafaryngeal and retroauricular regions. The biopsy result from LAP was lymphoma. Patient's lymphoma treatment completed.

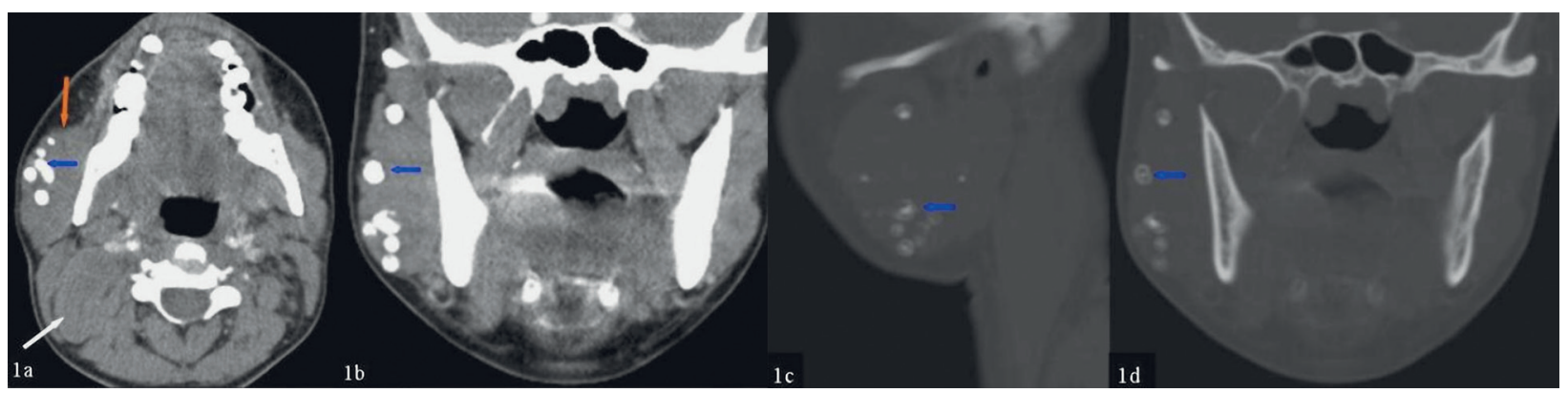

Figure 1 a-d: a-b: Axial and coronal paranchymal window, c-d: sagittal and coronal bone window on CT scans, it is seen ill- defined mass of heterogeneous density in the right masseter (orange arrow) and there are multiple calcified lesions (phlebolith) (blue arrows) in the mass. Due to lymphoma, multiple LAPs are seen in bilateral parapharyngeal and retroauricular spaces (white arrow).

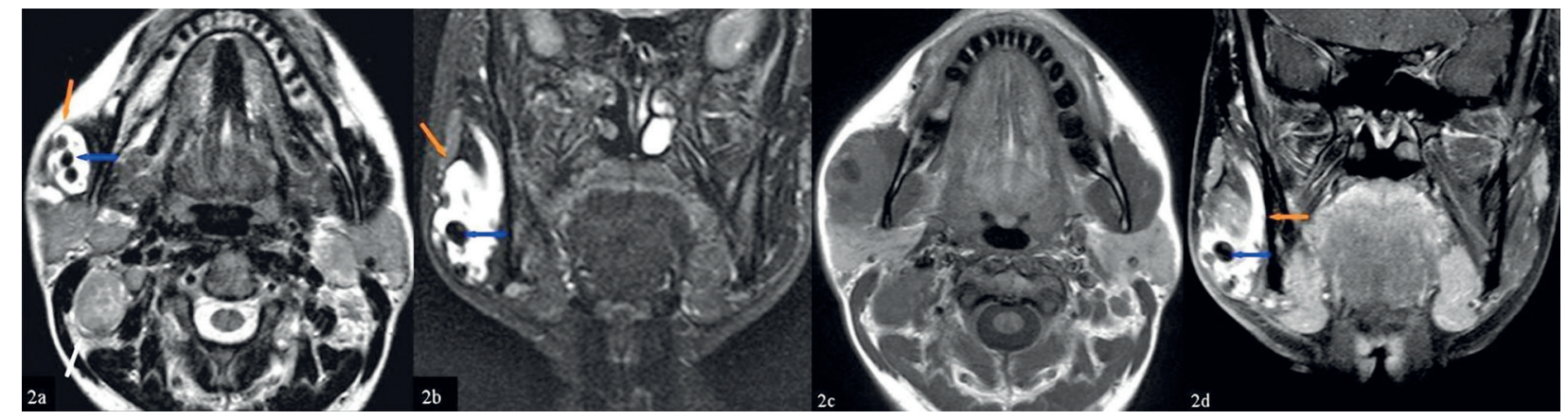

Figure 2 a-d: a-b: Axial and coronal plane T2 weighted c: axial plane T1 weighted sequence, the mass in the masseter muscles, heterogeneous signal intensity on T1 and T2 weighted sequence and mass appeared as high signal intensity lobules that resemble a brunch of grapes on T2 weighted images (orange arrows). There was punctuate or reticular low signal intensity areas that represent fibrous tissue, fast flow within the vessel or foci of calcifications due to phlebolithes (blue arrows), It is seen multiple LAPs in the bilateral parapharyngeal and retro auricular regions (white arrow). d: post contrast coronal plane T1 weighted sequence, the mass enhanced after intravenous contrast material.

\section{Case 2}

A 16 years-old male patient with complaints of dental diseases applied to the dental clinic. His right cheek has been swelling and having increasing pain at certain times since he was 7 years-old. Via physical examination the swelling was determined over the right parotid region. It was a mobile and multilobulated surface. His facial movement, intraoral examinations, and overlying skin were normal.
Via ultrasound examinations, we concluded that there was heterogeneous echogenicity cystic mass with solitary posterior acoustic shadowing the calcified nodular areas in the right masseter muscle(Fig. 3a-b). Later Computed tomography (CT) was planned for diagnosis, then it was found that there was a mass lesion at the location of the right masseter muscle there were solitary calcified area within the mass lesion(Fig. 4a-b). 


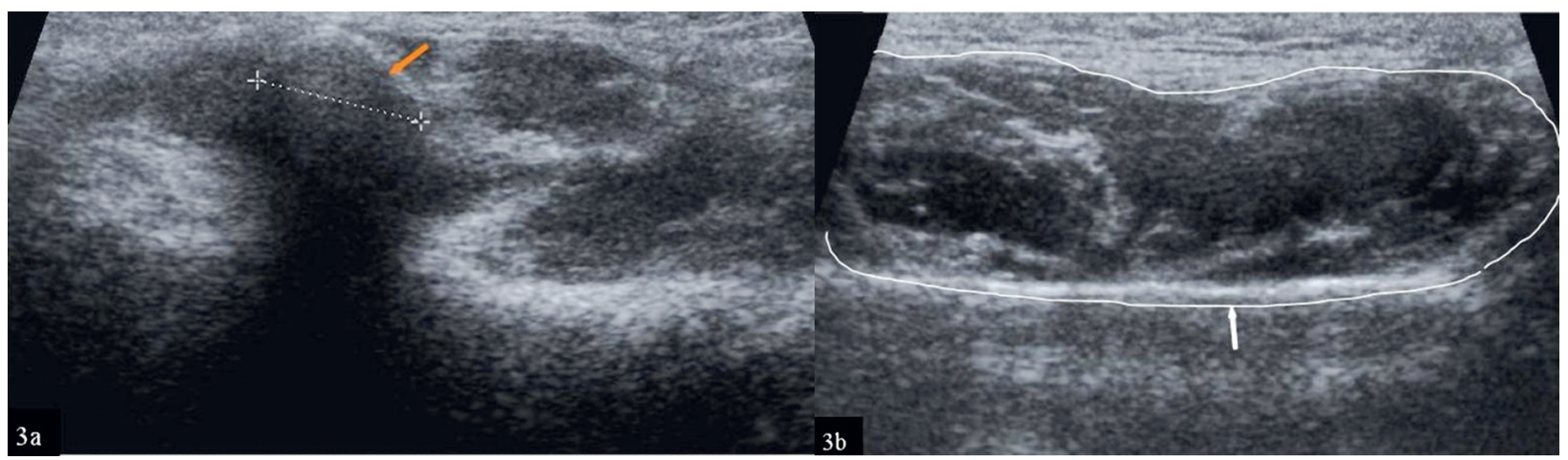

Figure 3 a-b: With USG examination, there was heterogeneous echogenicity cystic mass (in white line) with posterior acoustic shadowing of the calcified nodular area (orange arrow) in the right masseter muscle.

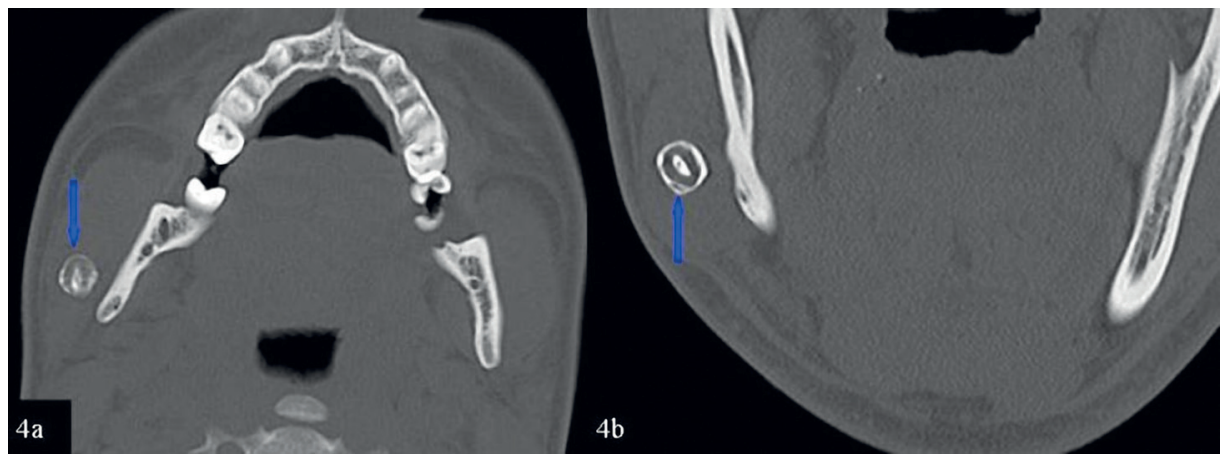

Figure 4 a-b: Axial and coronal bone window on the CT scans, mass lesion at the localized of the right masseter muscle, there were solitary calcified area within the mass lesion (blue arrow).

Assessing the detailed structure of the lesion, a magnetic resonance imaging (MRI) examination was performed. The mass appeared to be high signal intensity lobules that resemble a brunch of grapes on T2 weighted images. There were punctuate or reticular low signal intensity areas that represent fibrous tissue. Fast flow within the vessel or foci of calcifications due to phlebolithes was also identified. Our case has characteristic and pathognomonic signs of hemangioma like a brunch of grapes and phlebolith (Fig. 5a-d).

Because of his normal facial movement, intraoral examinations, and normal overlying skin, in both cases, no treatment was required for hemangiomas.

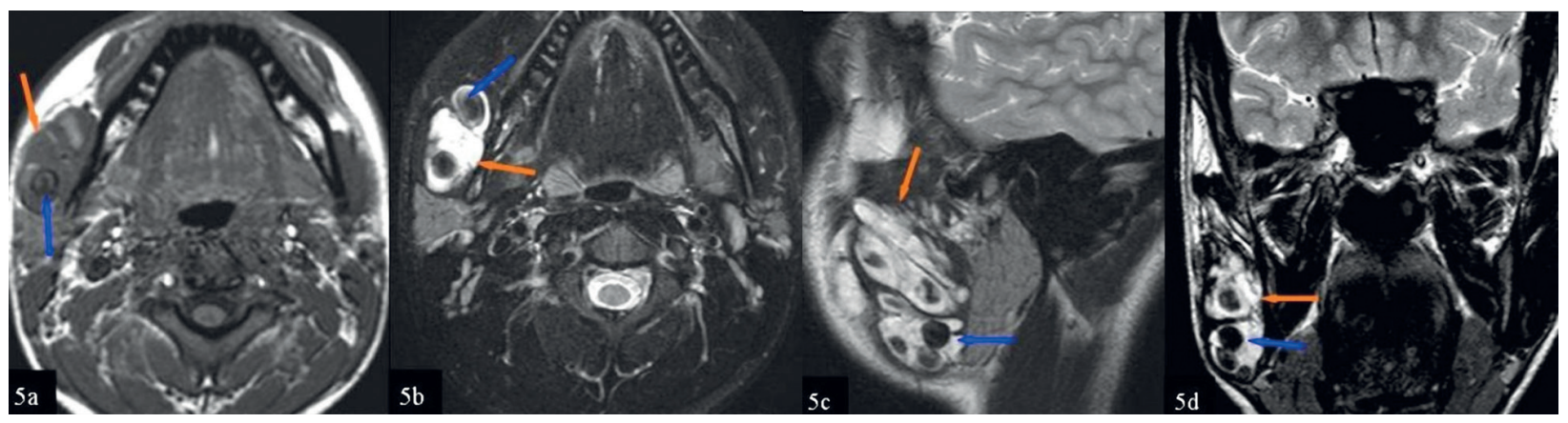

Figure 5 a-d: a: axial T1 weighted, b-d: axial, sagittal and coronal plane T2 weighted sequence, the mass in the masseter muscles, heterogeneous signal intensity on T1 and T2 weighted sequence and mass appeared as high signal intensity lobules that resemble a brunch of grapes on T2 weighted images (orange arrows). There was punctuate or reticular low signal intensity areas that represent fibrous tissue, fast flow within the vessel or a foci of calcifications due to phlebolith (blue arrow). 


\section{Case 3}

A 65 year-old woman appeared in ENT clinic with a facial swelling over bending anteriorly (for praying) and in an emotional situation. Because of the unexpected facial disfigurement in social situations, patient asked for a solution to her problem. Investigation suggested a vascular lesion of $3 \times 4 \mathrm{~cm}$ on the right cheek. Surgical removal planned and uneventful excision of the lesion through sublabial approach was performed. Specimen's pathological exam was reported as a multilobulated $3,5 \times 3,5 \mathrm{~cm}$ angiomatous nodular lesion.

\section{DISCUSSION}

Intramuscular hemangioma (IMH) is a proliferation of benign vascular channels within the skeletal muscle. ${ }^{1}$ It is believed to be hamartomatous, congenital neoplasm. They are uncommon in the head and neck region and arising most frequently from masseter and trapezius muscle. $60 \%$ is in these muscles. ${ }^{5}$ Other sites in the head and neck are pterygoid, thyrohyoid, larynx, sternocleidomastoid, orbital and posterior neck muscles. ${ }^{5,6}$ Intramuscular hemangiomas are commonly seen among adolescents and young adults, especially before the age of 30; however, they may affect older patients..$^{1,2}$ One of our cases had the patient at the age of 16 , and the other patients in the other 2 cases were 50 and 65 years-old.

Preoperative diagnosis is difficult due to the fact that IMH have nonspecific clinical findings. $\mathrm{IMH}$ has a pseudo edge, and is usually well circumscribed and may infiltrate insidiously the muscle. For long time it can stay undetected, until its sudden growth which causes incremental pain or/and cosmetic deformity. IMH presents a slowly enlarging mass generally with a normal overlying skin, yet also may have a reddish blue discoloration. Overlying skin of our cases was normal and there was no significant cosmetic problem in two cases; however in one case, a functional/positional significant lesion treated by a surgical intervention.

Intramuscular hemangioma is a non-capsulated mass and locally invasive tumor involving a growth along a plan of least resistance.

Diagnosis is made by physical examination, plain radiography, USG, CT, MRI, and angiography. ${ }^{7,8}$ By physical examination, the most common initial presentation, there is a palpable, usually painless mass in the muscle. ${ }^{5} \mathrm{~A}$ variety of tumors can be confused clinically with an IMH. These are salivary neoplasms, lymphangiomas, rhabdomyosarcomas, masseteric hypertrophy, and schwannoma.
Plain radiography is not important for diagnosis but can demonstrate tortuous vascular spaces, phleboliths.3-5 According to ultrasound examinations, there was heterogeneous echogenicity cystic mass with posterior acoustic shadowing secondary of the calcified nodular areas.

$\mathrm{CT}$ is a good imaging modality and IMH is seen well circumscribed mass in which may enhance after administering the contrast material. Phlebolith is well seen via CT, but it unable to define tissue planes and the vascularity of the lesion. ${ }^{5,6}$

MR imaging is a useful noninvasive technique for examinations of soft tissue and hemangioma because of its superior soft tissue contrast and multiplanar capability. MR imaging findings in hemangioma are frequently diagnostic. ${ }^{5,9}$ Hemangioma generally appears as high signal intensity lobules that resemble a brunch of grapes on T2 weighted images. Hemorrhagic and calcified areas and fatty tissue that located in the hemangioma are responsible of heterogeneous signal intensity on T1 and T2 weighted sequences. Punctuate or reticular low signal intensity areas represent fibrous tissue, fast flow within the vessel or foci of calcifications. Phleboliths appear as circular areas of low signal intensity. Our cases' findings of USG, CT, and MRI were identical with the literature and our cases have characteristic and pathognomonic signs for hemangioma like a brunch of grapes and phlebolith.

Angiography is another imaging modality and may delineate the vascular nature of an IMH and feeding artery. $3,5,9$ Treatment options for symptomatic hemangiomas have included steroids, radiation therapy, surgical resection, arterial ligation, and transcatheter arterial embolization(TAE). TAE has been used in the treatment of ruptured hemangiomas, diffuse hemangiomatosis, and symptomatic hemangiomas. However, different embolic materials have been used for TAE in hemangiomas, such as gelfoam, steel coils, polyvinyl alcohol, and isobutyl cyanoacrylate. ${ }^{10}$ Asymptomatic hemangiomas can be traced and none surgical excision is necessary. In one of our cases a surgical treatment was asked while 2 cases were kept for follow-up. Surgical treatment is necessary especially if there is a rapid growth, uncontrolled pain, aesthetic problems, thrombocytopenia, functional impairment, necrosis overlying skin, and suspicion of malignancy. The optimal management is a wide surgical excision that includes normal muscle beyond the gross limits of the tumor. Cosmetic problems and functional disabilities are minimized after excision, even after significant removal of surrounding normal muscle. ${ }^{3}$ 
Although IMH is rare in the head and neck, it should be considered in the differential diagnosis of masses in these regions. Its diagnosis is difficult because of its nonspecific sign. USG, CT, and MRI are useful imaging modalities in diagnosis of $\mathrm{IMH}$. Management of intramuscular hemangioma should be individualized based on tumor location and extent, tumor growth rate, anatomical accessibility, patient age, and cosmetic considerations. Some of the patients can be observed via accuracy of MRI especially in young children.

In conclusion, IMH is rare in the head and neck or oral cavity, and it should be considered in the differential diagnosis of masses in these regions. Its diagnosis is difficult because of its rarity and nonspecific sign.

\section{REFERENCES}

1. Fletcher CD, Unni KK, Mertens F, editors. World health organization: Classification of tumors. Pathology and genetics of tumors of soft tissue and bone. Lyon: IARC Press 2002.

2. Weiss SW, Goldblum JR. Benign tumors and tumor-like lesions of blood vessels. In: Weiss SW, Goldblum JR, edi tors. Enzinger and Weiss's soft tissue tumors. $4^{\text {th }}$ ed. St. Louis: C.V. Mosby;2001. p.837-90.
3. Wolf GT, Daniel F, Krause CJ, Kaufman RS. Intramuscular hemangioma of the head and neck. Laryngoscope 1985; 95(2):210-3.

4. Allen PW, Enzinger FM. Hemangioma of skeletal muscle. An analysis of 89 cases. Cancer 1972; 29(1):8-22.

5. Rossiter JL, Hendrix RA, Tom LW, Potsic WP. Intramuscular hemangioma of the head and neck. Otolaryngol Head Neck Surg 1993;108(1):18-26.

6. Durucu C, Karataş E, Bağlam T, Çevik C, Kanlıkama M. Erişkin ses teli hemanjiyomu. J Clin Exp Invest 2010;2(3): 323-26.

7. Dubois J, Patriquin HB, Garel L, et al. Soft-tissue hemangiomas in infants and children: diagnosis using Doppler sonography. AJR Am J Roentgenol 1998; 171(1):247-52.

8. Paltiel HJ, Burrows PE, Kozakewich HP, Zurakowski D, Mulliken JB. Soft-tissue vascular anomalies: utility of US for diagnosis. Radiology 2000; 214(3):747-54.

9. Odabasi AO, Metin KK, Mutlu C, Başak S, Erpek G. Intramuscular hemangioma of the masseter muscle. Eur Arch Otorhinolaryngol 1999; 256(7):366-69.

10. Srivastava DN, Gandhi D, Seith A, Pande GK, Sahni $P$. Transcatheter arterial embolization in the treatment of symptomatic cavernous hemangiomas of the liver: a prospective study. Abdom Imaging 2001;26(5):5104. 